\title{
Ансамбли NV- центров квантового качества в высокочистом алмазе после горячей имплантации и высокотемпературного отжига под давлением
}

\author{
С.Н. Подлесный ${ }^{1}$, И.А. Карташов ${ }^{1}$, В.П. Попов ${ }^{1}$, И.Н. Куприянов ${ }^{2}$ Ю.Н. Пальянов ${ }^{2}$ \\ ${ }^{1}$ ФГБУН Институт физики полупроводников им. А.В. Ржанова СО РАН \\ 630090, пр. Ак. Лаврентьева 13, Новосибирск, Россия \\ ${ }^{2}$ ФГБУН Институт геологии и минералогии им. В.С. Соболева СО РАН, \\ 630090, пр. Ак. Коптюга 3, Новосибирск, Россия \\ тел.: +7(383)333-25-37, эл. почта: ророv@isp.nsc.ru
}

DOI 10.34077/RCSP2021-73

Квантовые устройства на спинах точечных дефектов широкозонных полупроводниках, например, NV центров и их ансамблях в алмазе привлекательны возможностью работы при комнатных температурах, однако время спиновой релаксации $\mathrm{T}_{2}{ }^{*}$ зависит от других дефектов и обычно $\mathrm{T}_{2}{ }^{*}<<\mathrm{T}_{2}-$ времени когерентной релаксации на узловых атомах азота Ns. Проблемой остается их создание в заданной области, единственным способом которого является имплантация, создающая массу других дефектов. Решить проблему “квантового качества" можно двумя способами. Во-первых, формированием сверхрешеток из узловых атомов азота с регулярными рельефом для их встраивания при росте из газовой фазы [1], а затем захватом вакансий, сформированных при локальном облучении и нагреве сфокусированным пучком, в соседние с азотом узлы [2]. Во-вторых, внедрением одиночных ионов $\mathrm{N}+$ имплантерами с регистрацией фотонной или электронной эмиссии от вошедшего в мишень иона или заряда на её поверхности, управляющих процессом переноса ионного пучка в новую точку $[3,4]$.

Ансамбли NV- центров создавались нами в высокочистом <111> алмазе типа ІІа “горячей” имплантацией ионов азота $\mathrm{N}^{+} \mathrm{c}$ энергиями 50, 100, 150, 200, 300 кэВ разными флюенсами при $\mathrm{T}_{\mathrm{imp}}=450-550^{\circ} \mathrm{C}$ до концентраций азота Ns $\sim 5-150$ ppm в 250 нм слое согласно расчетам C-SRIM и термообработкой при $1200-1500^{\circ} \mathrm{C}$ в вакууме или под давлением 6 ГПа (НРНТ) для отжига оптически активных дефектов. В результате оставались лишь $\mathrm{N}_{\mathrm{s}}{ }^{0}, \mathrm{NV}, \mathrm{N}_{2} \mathrm{~V}$ и $\mathrm{N}_{3} \mathrm{~V}$ центры, концентрации каждого из которых были на порядок меньше предыдущего. При максимальной температуре отжига $1500^{\circ} \mathrm{C}$ в вакууме никаких дефектов, кроме $\mathrm{NV}$ и $\mathrm{SiV}$ центров на уровне $\sim 1 \mathrm{ppb}$ нет. При НРНТ

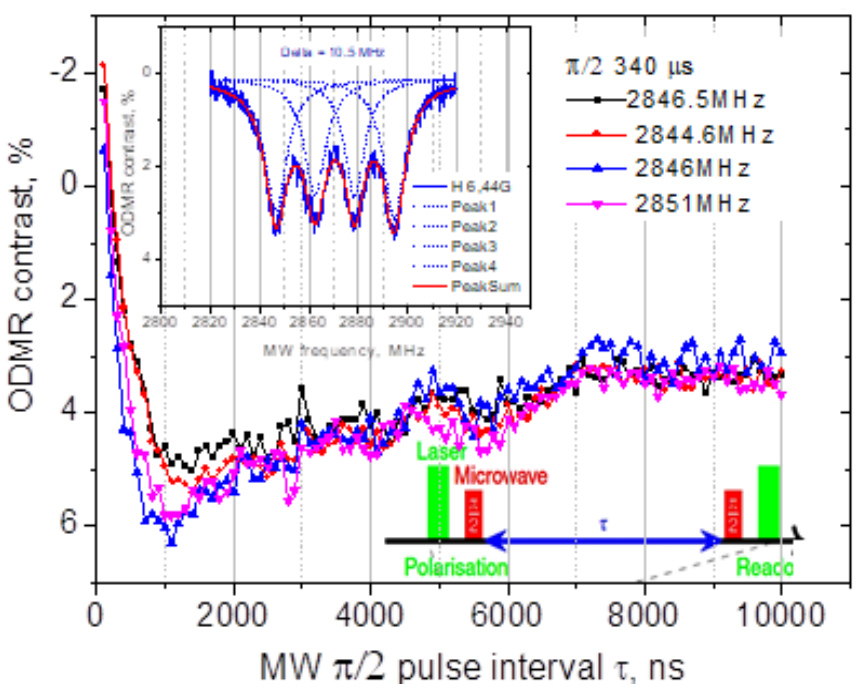
отжиге содержание NV центров в слое было $>0.2$ ppm или более чем на два порядка выше по сравнению с отжигом в вакууме.

Данные импульсного оптически детектируемого магнитного резонанса, измеренные при комнатной температуре (Рис.), показали, что время спиновой релаксации $\mathrm{T}_{2}{ }^{*}=0.6-1.2$ мкс соответствует экспериментальной и теоретической зависимости для $\left(\mathrm{T}_{2}\right)^{-1}=\mathrm{BN}_{\mathrm{s}}{ }^{0}$, тогда как обычно экспериментально выполняется соотношение $\mathrm{T}_{2}{ }^{*}<<\mathrm{T}_{2}$ при теоретической величине $\mathrm{T}_{2} / \mathrm{T}_{2}{ }^{*} \approx 16$ за счет неспаренного электрона доноров $\mathrm{N}_{\mathrm{s}}{ }^{0}$ [5]. Вероятной причиной повышенного содержания $\mathrm{NV}$ центров при HРНT отжиге является рост термодинамически равновесной концентрации вакансий [6]. Близость времен $\mathrm{T}_{2}{ }^{*}$ и $\mathrm{T}_{2}$ может быть связана с высокой степенью ионизации доноров $\mathrm{N}_{\mathrm{s}}{ }^{0}$, которые ЭПР пассивны в ионизованном состоянии $\mathrm{N}_{\mathrm{s}}{ }^{+}$.

\section{Лumepamypa}

[1] J. Achard et al. // J. Phys. D: Appl. Phys. 53, 313001, 2020.

[2] M. Capelli, et al. // Carbon, 143, C. 714-719, 2019.

[3] P. Räcke et al. // New Journ. Phys., 22(8), 083028, 2020.

[4] S. Pezzagna, Meijer, J. Applied Physics Reviews, 8(1), 011308, 2021.

[5] J.F. Barry et al. // Rev. Mod. Phys. 92, 015004, 2020.

[6] S. Rubanov, et al. // Diamond and Related Materials, 63, p.143-147, 2016. 